\title{
Impact of emergency oral rabies vaccination of foxes in northeastern Italy, 28 December 2009-20 January 2010: preliminary evaluation
}

K Capello ${ }^{1}$, P Mulatti ${ }^{1}$, A Comin $^{1}$, L Gagliazzo ${ }^{1}$, V Guberti $^{2}$, C Citterio ${ }^{1}$, P De Benedictis ${ }^{1}$, M Lorenzetto ${ }^{1}$, C Costanzi ${ }^{3}$, P Vio $^{4}$,

P Zambotto ${ }^{5}$, G Ferri' ${ }^{6}$, F Mutinelli ${ }^{1}$, L Bonfanti ${ }^{1}$, S Marangon (smarangon@izsvenezie.it) ${ }^{1}$

1. Istituto Zooprofilattico Sperimentale delle Venezie - IZSVe, National Reference Centre for Rabies, Legnaro (Padova), Italy

2. Institute for Environmental Protection and Research - ISPRA, Ozzano Emilia (Bologna), Italy

3. Veterinary Service, Autonomous Province of Trento, Trento, Italy

4. Regional Unit of Animal Health and Food Safety, Dorsoduro (Venezia), Italy

5. Veterinary Service, Autonomous Province of Bolzano, Bolzano, Italy

6. Ministry of Health, General Direction for Animal Health, Roma, Italy

Citation style for this article:

Capello K, Mulatti P, Comin A, Gagliazzo L, Guberti V, Citterio C, De Benedictis P, Lorenzetto M, Costanzi C, Vio P, Zambotto P, Ferri G, Mutinelli F, Bonfanti L, Marangon S. Impact of emergency oral rabies vaccination of foxes in northeastern Italy, 28 December 2009-20 January 2010: preliminary evaluation. Euro Surveill. 2010;15(28):pii=19617. Available online: http://www.eurosurveillance.org/ViewArticle.aspx?Articleld=19617

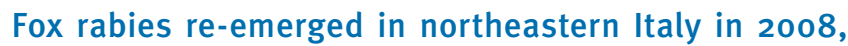
in an area bordering Slovenia. In 2009, the infection spread westward to Veneto region and in 2010 to the provinces of Trento and Bolzano. Aerial emergency oral fox vaccination was implemented in the winter 200910. Since this vaccination was performed at altitudes below the freezing level, a statistical analysis was conducted to evaluate its impact. Of the foxes sampled following the vaccination campaign, $77 \%$ showed a rabies antibody titre of $\geq 0.5 \mathrm{IU} / \mathrm{ml}$.

\section{Background}

In October 2008, rabies infection was diagnosed in a red fox (Vulpes vulpes) in the municipality of Resia (Region of Friuli Venezia Giulia, northeastern Italy) [1]. Friuli Venezia Giulia had been affected by rabies in the 1970 s and 1980 s and, more recently, in the period from 1991 to 1995 [2]. Oral fox vaccination campaigns using SAD B19 vaccine baits [3] were conducted in these areas in 1989 and from 1992 to 2004 , and the last documented animal to be infected with rabies was a fox diagnosed in December 1995 in the province of Trieste (Friuli Venezia Giulia), in an area bordering Slovenia. Since then, no other cases had been reported, and since 1997 Italy had been classified as rabies-free.

Following the identification of the infected fox in October 2008, three oral fox vaccination campaigns were conducted in Friuli Venezia Giulia, providing manual distribution of vaccine baits [4]. However, in November 2009, fox rabies spread westward to Veneto region and reached the autonomous provinces of Trento and Bolzano in spring 2010.

Following reports of infection in Veneto region, an emergency vaccination campaign in accordance with the European Union (EU) recommendations [3] was implemented in a large area that included the recently affected regions (Figure 1 ).

In particular, from 28 December 2009 to 20 January 2010, SAD B19 vaccine baits (Fuchsoral, IDT Biologika) were distributed by helicopter in an area of approximately 9,000 km², using a satellite-navigated and computer-supported automatic bait dropping system [5]. An electronic metronome connected to a GPS allowed adjusting the dropping tempo to the speed of the helicopter, permitting an estimated bait coverage of 25-30 baits $/ \mathrm{km}^{2}$. Given that there was no precise information on the size or structure of Italy's fox population, we applied the average bait density recommended for high fox population densities (i.e. 20-30 baits $/ \mathrm{km}^{2}$ ) [6]. Vaccine baits were distributed only at altitudes below the freezing level (1,000 $\mathrm{m}$ above sea level (asl)), taking into account the average winter temperature in the Alps.

Here we provide the results from monitoring the emergency vaccination campaign, in terms of the number of foxes that achieved protective antibody titres [6], and we compare the number of laboratory-confirmed cases of rabies in red foxes in the period before and after the vaccination campaign.

\section{Methodology}

The study period ranged from the date that the first case was reported in Veneto region (17 November 2009) to the date of conclusion of the study monitoring the effectiveness of the emergency oral fox vaccination campaign (9 May 2010). The study period was then divided into a pre-vaccination period, taking into account the time needed for the foxes to develop antibodies, and a post-vaccination period. The cut-off date chosen to distinguish these periods was 4 March 2010 (i.e. 30 days after the end of bait distribution). The 
tested foxes were those that had been found dead or killed by hunters in the study area (it is mandatory to bring these animals to the National Reference Centre for Rabies at Legnaro Institute).

\section{Case definition}

A case of rabies was defined by a positive result in the fluorescent antibody test (FAT) followed by a confirmatory test, i.e. tissue culture isolation (TCIT) or mouse inoculation test (MIT) [6].
The immune response of foxes to oral vaccination was determined by a fluorescent antibody virus neutralisation test (FAVN test) [6]. All analyses were conducted in the laboratory of the National Reference Centre for Rabies at Legnaro Institute.

\section{Results of the winter emergency vaccination campaign}

Of 1,917 red foxes tested, 1,324 were collected in the pre-vaccination period and 593 in the post-vaccination period. Rabies was laboratory-confirmed in 170 of the 1,917 foxes (Figure 1). Of these 170, 100 (58.8\%) were

\section{FIGURE 1}

Areas with laboratory-confirmed cases of rabies in red fox, northeastern Italy, 17 November 2009-9 May 2010

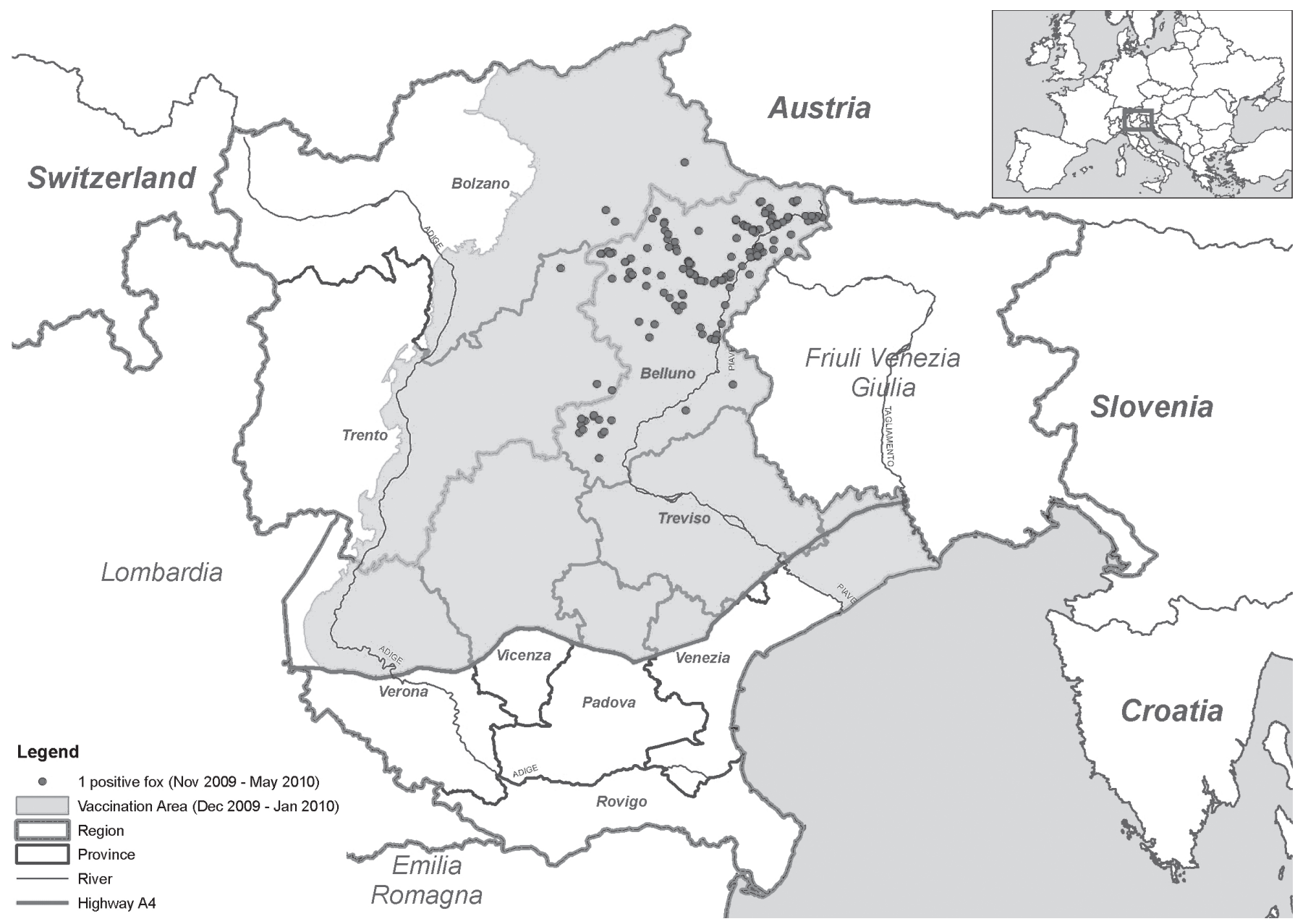

Source: National Reference Centre for Rabies, Istituto Zooprofilattico Sperimentale delle Venezie - IZSVe, Legnaro (Padova), Italy

\section{TABLE}

Rabies cases by period and altitude at which the fox was found, northeastern Italy, 17 November 2009-9 May 2010 (N=170)

\begin{tabular}{|c|c|c|c|c|c|c|}
\hline \multirow{3}{*}{ Period } & \multicolumn{6}{|c|}{ Altitude } \\
\hline & \multicolumn{2}{|c|}{ Below $900 \mathrm{~m}$ asl } & \multicolumn{2}{|c|}{ Above $900 \mathrm{~m}$ asl } & \multicolumn{2}{|c|}{ Total } \\
\hline & Number & Percentage & Number & Percentage & Number & Percentage \\
\hline Pre-vaccination & 41 & $41 \%$ & 59 & $59 \%$ & 100 & $100 \%$ \\
\hline Post-vaccination & 11 & $16 \%$ & 59 & $84 \%$ & 70 & $100 \%$ \\
\hline Total & 52 & $31 \%$ & 118 & $69 \%$ & 170 & $100 \%$ \\
\hline
\end{tabular}


diagnosed in the pre-vaccination period and 70 in the post-vaccination period. All of the rabid foxes were found dead or shot by hunters in mountainous areas, at altitudes ranging from 398 to $2,224 \mathrm{~m}$ asl. The rabid foxes were found at the lower mean altitude (971 m asl) during the pre-vaccination period, compared to the post-vaccination period (1,206 $\mathrm{m}$ asl) (one-tailed t-test, $p$ value $(0.001)$.

Given that vaccine baits were distributed at altitudes below the freezing level (which corresponds to 1,000 $\mathrm{m}$ asl), a conservative cut-off value of $900 \mathrm{~m}$ asl was selected to identify the zones covered by vaccination ( $\leq 900 \mathrm{~m} \mathrm{asl}$ ) and those not covered ( $>900 \mathrm{~m}$ asl). During the pre-vaccination period, rabies cases were almost equally distributed below and above $900 \mathrm{~m}$ asl ( $41 \%$ and $59 \%$ of cases, respectively), whereas in the post-vaccination period there was a significantly higher number of cases (84\%) found above $900 \mathrm{~m}$ asl (chi-square test, $p$ value $<0.001$ ) (Table). To determine whether this difference was related to vaccination coverage, the homogeneity of the sample in terms of vaccination period and altitude was investigated (the location in which the fox was collected was available for 1,809 of the 1,917 foxes tested). Given that there were no statistically significant differences in the number of foxes when comparing the two periods or the altitudes, the sample was considered to be homogeneous. We can thus hypothesise that the lower number of cases found below $900 \mathrm{~m}$ asl during the post-vaccination period was related to vaccination coverage.

With regard to temporal trends, there were no differences in the weekly number of cases by altitude in the pre-vaccination period (Mann-Whitney test, $p$ value $=0.078$ ), whereas significant differences were found in the post-vaccination period ( $p$ value $<0.01$ ) (Figure 2).

Of the 593 foxes collected in the post-vaccination period, 203 (i.e. those coming from the vaccination area and negative in the FAT assay) were tested by means of FAVN test to investigate the effectiveness of the vaccination campaign. The mean antibody titre was $2.0 \mathrm{IU} / \mathrm{ml}(\mathrm{min} 0.1-\max 16.6 \mathrm{IU} / \mathrm{ml})$. Of these 203 foxes, $156(77 \%)$ were considered as immunised, in that their antibody titre exceeded the level considered to be protective by the OIE Manual of Diagnostic Tests and Vaccines for Terrestrial Animals ( $\geq 0.5 \mathrm{lU} / \mathrm{ml}$ ) [6].

\section{Other rabies control measures}

In addition to the emergency vaccination campaign, preventative measures were implemented in the affected areas, including compulsory rabies vaccination of dogs and domestic herbivores at risk of infection (i.e. cows, horses, sheep and goats kept outdoors), movement restrictions of dogs, and enhancement of surveillance in the wild animal population. Furthermore, an information campaign was conducted in order to increase

\section{FIGURE 2}

Weekly trend of laboratory-confirmed cases of rabies by period and altitude at which the fox was found, northeastern Italy, 17 November 2009-9 May $2010(\mathrm{~N}=170)$

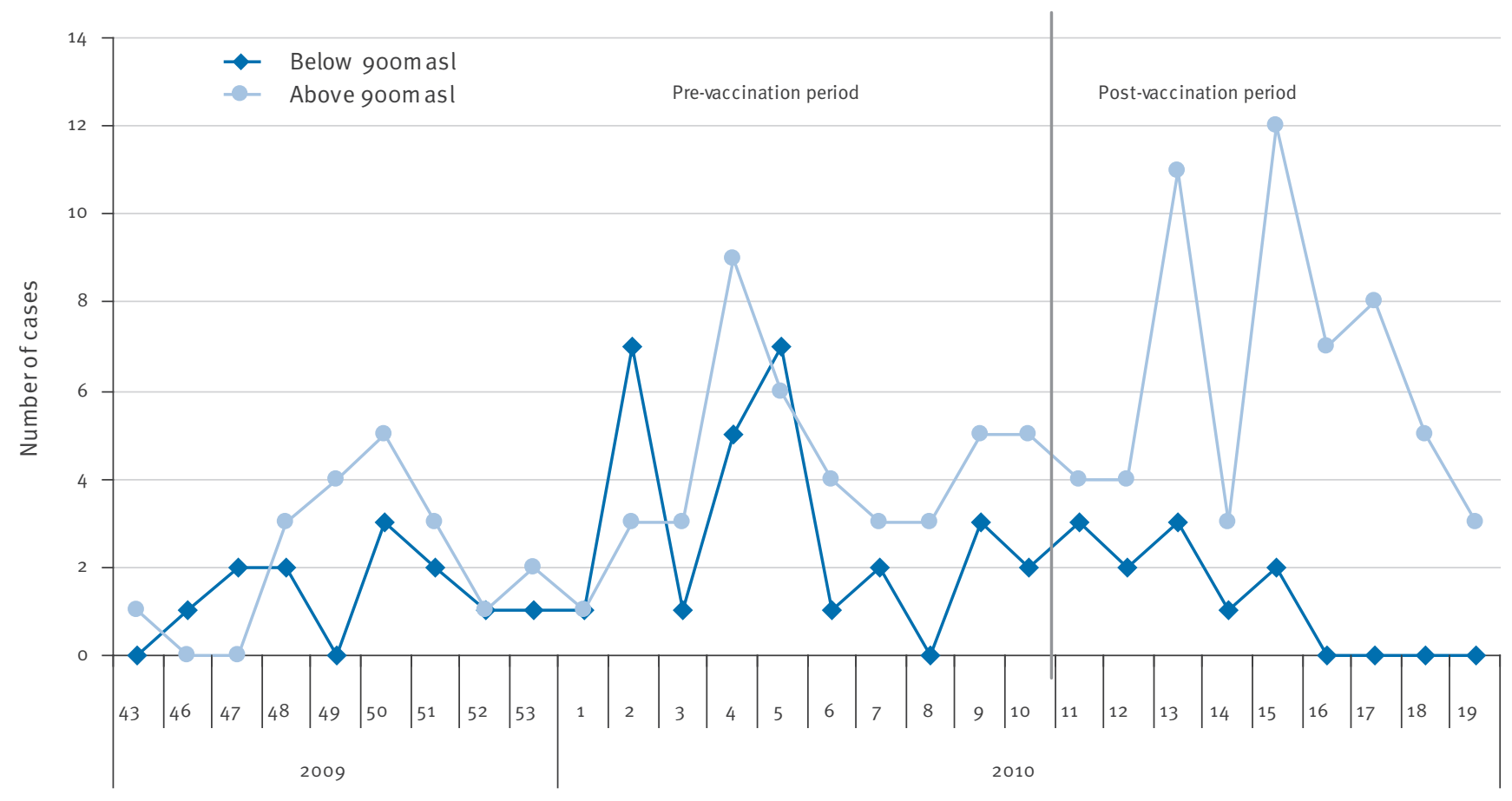

Week 
risk-awareness of the population and improve preparedness of health services.

\section{Conclusions}

The emergency OFV campaign was carried out during the winter, under unfavourable weather conditions. In fact, it is not recommended that vaccination be performed at temperatures below $0{ }^{\circ} \mathrm{C}$ because frozen vaccines do not induce a sufficient immune response and the virus titre may decrease as a result of freezingthawing cycles [3]. Despite this and the fact that the size and structure of the fox population are unknown, the campaign led to satisfactory immune coverage ( $77 \%)$ and the reduction of rabies incidence below $1,000 \mathrm{~m}$ asl. In the spring of 2010 , a second aerial OFV campaign was implemented in a larger geographical area (i.e. the entire region of Friuli Venezia Giulia, Trento and Bolzano, and part of the Veneto region). Based on the results of the present monitoring study, this campaign was expanded to cover altitudes up to $2,300 \mathrm{~m}$ asl and ended in mid-June.

\section{References}

1. De Benedictis P, Gallo T, Iob A, Coassin R, Squecco G, Ferri $\mathrm{G}$, et al. Emergence of fox rabies in north-eastern Italy. Euro Surveill. 2008;13(45):pii=19033. Available from: http://www. eurosurveillance.org/ViewArticle.aspx?Articleld =19033

2. Mutinelli F, Stankov S, Hristovski M, Seimenis A, Theoharakou H, Vodopija I. Rabies in Italy, Yugoslavia, Croatia, Bosnia, Slovenia, Macedonia, Albania and Greece. In: King AA, Fooks AR, Aubert M, Wandeler Al, editors. Historical perspectives of rabies in Europe and the Mediterranean Basin. Paris: World Organisation for Animal Health (OIE); 2004;93-118.

3. European Commission. The oral vaccination of foxes against rabies. Report of the Scientific Committee on Animal Health and Animal Welfare. 23 Oct 2002.

4. De Benedictis P, Capua I, Mutinelli F, Wernig JM, Arič T, Hostnik P. Update on fox rabies in Italy and Slovenia. Rabies Bulletin Europe. 2009;33(1): 5-7.

5. Selhorst T, Müller T, Bätza HJ. Epidemiological analysis of setbacks in oral vaccination in the final stage of fox rabies elimination in densely populated areas in Germany. Dev Biol (Basel). 2006;125:127-32.

6. World Organisation for Animal Health (OIE). Rabies. In: OIE Terrestrial Manual 2008. 6th ed. [Accessed 23 Jun 2010]. Available from: http://www.oie.int/eng/normes/ mmanual/2008/pdf/2.01.13_RABIES.pdf 